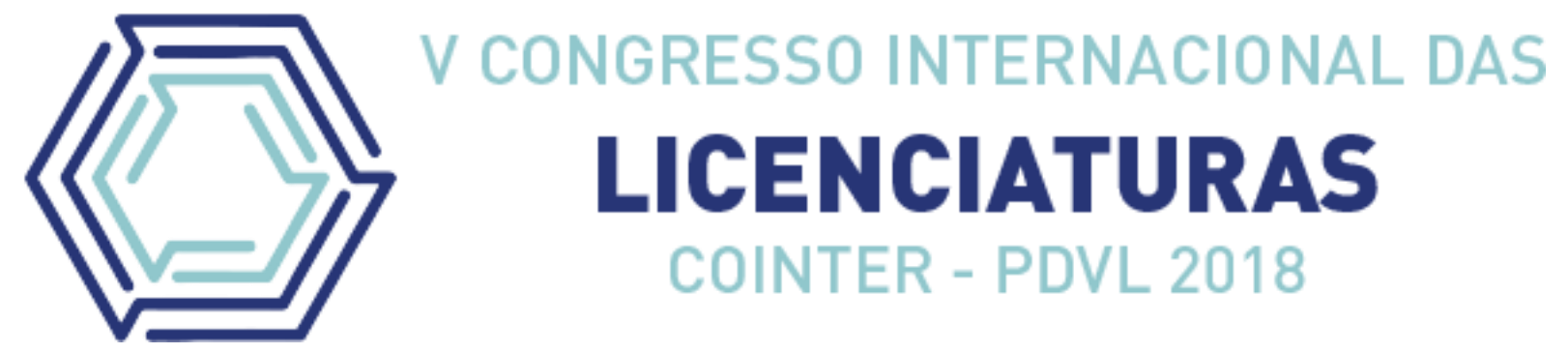

\title{
REFLEXÕES SOBRE A ANÁLISE DE ERROS NAS TEORIAS DE AQUISIÇÃO DE LÍNGUAS
}

\section{REFLECTIONS ON ERROR ANALYSIS IN LANGUAGE ACQUISITION THEORIES}

\author{
Apresentação: Comunicação Oral \\ Luciana Silva da Penha ${ }^{1}$; Girlene Moreira da Silva ${ }^{2}$; Carla Aguiar Falcão ${ }^{3}$ \\ DOI: https://doi.org/10.31692/2358-9728.VCOINTERPDVL.2018.00142
}

\begin{abstract}
Resumo
A aquisição e/ou aprendizagem da língua estrangeira e/ou segunda língua são processos com várias etapas pelas quais o aprendiz passa. Os erros, segundo Fernández (1995), por exemplo, fazem parte desse processo no qual algumas produções idiossincráticas são consideradas "normais". Esse novo ambiente linguístico será de erros e acertos no processo de aprendizagem chamado interlíngua (IL). Com o intuito de contribuir no processo de ensino e aprendizagem da língua espanhola, principalmente na formação de futuros professores, apresentamos este trabalho, que é parte de uma pesquisa em fase de realização, cujo objetivo geral é investigar e classificar erros na produção oral de alunos do Curso de Letras Espanhol do Campus Natal Central do Instituto Federal de Educação, Ciência e Tecnologia do Rio Grande do Norte (IFRN). Reflexionaremos, aqui, sobre as questões teóricas que permeiam nosso trabalho, baseando-nos, principalmente, nos estudos de Baralo (2004), Cesteros (2006), Sonsoles Fernández (1997) e Griffin (2005). A referida pesquisa pode ser classificada como descritiva, já que busca observar e registrar os fatos ocorridos de modo a descrevê-los sem que haja interferência por parte do pesquisador. Já no que se refere à abordagem do problema e análise dos dados, classificamos nossa pesquisa como quanti-qualitativa, pois quantificaremos de forma sistemática e objetiva a recorrência da aparição de erros nos dados coletados nas entrevistas feitas aos sujeitos da pesquisa para categorizá-los, ao mesmo tempo em que analisaremos e interpretaremos os resultados de forma mais complexa, buscando identificar a possível causa do erro, ou seja, em numa perspectiva qualitativa. Por fim, entendemos que os erros são considerados normais no processo de interlíngua e são usados, por vezes, pelos alunos, como estratégias para a aquisição da língua meta.
\end{abstract}

Palavras-Chave: Aquisição de Segundas Línguas, Oralidade, Análise de Erros.

\footnotetext{
${ }^{1}$ Licenciatura em Letras Espanhol, Instituto Federal de Educação, Ciência e Tecnologia do Rio Grande do Norte, luhsilva1404@gmail.com

${ }^{2}$ Doutora em Linguística Aplicada, Instituto Federal de Educação, Ciência e Tecnologia do Rio Grande do Norte, girlene.moreira@ifrn.edu.br

${ }^{3}$ Doutora em Estudos da Linguagem, Instituto Federal de Educação, Ciência e Tecnologia do Rio Grande do Norte, carla.falcao@ifrn.edu.br
} 


\begin{abstract}
The acquisition and / or learning of the foreign language and / or second language are processes with several stages through which the learner passes. Errors, according to Fernández (1995), for example, are part of this process in which some idiosyncratic productions are considered "normal". This new linguistic environment will be of errors and correctness in the learning process called Interlingua (IL). In order to contribute to the teaching and learning process of the Spanish language, especially in the training of future teachers, we present this work, which is part of an ongoing research, whose general objective is to investigate and classify errors in the oral production of students of the Course of Spanish Literature of the Central Natal Campus of the Federal Institute of Education, Science and Technology of Rio Grande do Norte (IFRN). We will reflect here on the theoretical issues that permeate our work, based mainly on the studies of Baralo (2004), Cesteros (2006), Sonsoles Fernández (1997) and Griffin (2005). This research can be classified as descriptive, since it seeks to observe and record the facts that occurred in order to describe them without interference by the researcher. Regarding the approach to the problem and data analysis, we classified our research as quanti-qualitative, as we will quantify in a systematic and objective way the recurrence of the appearance of errors in the data collected in the interviews made to the subjects of the research to categorize them, while at the same time analyzing and interpreting the results in a more complex way, seeking to identify the possible cause of the error, that is, in a qualitative perspective. Finally, we understand that mistakes are considered normal in the interlanguage process and are sometimes used by students as strategies for the acquisition of the target language.
\end{abstract}

Keywords: Acquisition of Second Languages, Orality, Error Analysis.

\title{
Introdução
}

A aquisição e/ou aprendizagem da língua estrangeira e/ou segunda língua são processos com várias etapas pelas quais o aprendiz passa. Os erros, segundo Fernández (1995), por exemplo, fazem parte desse processo no qual algumas produções idiossincráticas são consideradas "normais". Esse novo ambiente linguístico será de erros e acertos no processo de aprendizagem chamado interlíngua (IL).

No processo de interlíngua, é sabido que os alunos cometem variados erros na escrita e na fala da língua meta até chegar a um nível maior de domínio da língua. Para muitos alunos, a comunicação oral se torna um momento difícil, principalmente devido aos erros que esses aprendizes comentem no momento de falar. Esses erros, inclusive, podem levar a interferências no ato de comunicação, fazendo com que o objetivo de ser compreendido não seja alcançado. 
Para futuros professores, a responsabilidade de superar os erros se torna ainda maior, pois além de usarem o idioma para a comunicação, também serão responsáveis por transmitir os meios de aquisição do idioma a outras pessoas.

Com o intuito de contribuir no processo de ensino e aprendizagem da língua espanhola, principalmente na formação de futuros professores, apresentamos este trabalho, que é parte de uma pesquisa em fase de realização, cujo objetivo geral investigar e classificar erros na produção oral de alunos do Curso de Letras Espanhol do Campus Natal Central do Instituto Federal de Educação, Ciência e Tecnologia do Rio Grande do Norte (IFRN). Neste trabalho, buscamos refletir sobre as questões teóricas que permeiam nosso trabalho, baseandonos, principalmente, nos estudos de Baralo (2004), Cesteros (2006), Sonsoles Fernández (1997) e Griffin (2005). Por meio das teorias desses autores, respondemos aqui às duas questões: a) Podemos dizer que sempre que um aprendiz de uma segunda língua comete um erro é por causa da língua materna? e b) Como podemos diferenciar oralidade de oralização no processo de aquisição de línguas?

\section{Fundamentação Teórica}

\section{Produção oral na língua estrangeira: definição e características}

Marcuschi (2007) afirma que "fala e escrita são duas maneiras de funcionamento da língua..." (MARCUSCHI 2007, p.60) e elas estão intimamente relacionadas e têm como características comum o fato de terem processos de expressão e compreensão associados à interação, formando, portanto, as quatro habilidades linguísticas básicas, que são falar, escutar, escrever e ler (GÓMEZ, 2004). No entanto, apesar da proximidade entre essas destrezas, elas constituem, segundo Baralo (2000, p.10 apud GÓMEZ 2004), atividades autónomas e diferentes, são distintos seus modos de comunicação, contendo suas próprias características apesar de fazerem parte do mesmo sistema linguístico.

Ainda segundo a autora, na comunicação oral, haverá sempre a predominância das características "espontaneidade" e "fala imediata", visto que, na interação entre os falantes, o interlocutor dispõe de pouco tempo para pensar e assim interagir respondendo ao interlocutor, passando, portanto, por pressões psicológicas para que a interação venha em tempo ágil, e também tendo a preocupação de dar a resposta adequada diante da impossibilidade de desdizer o já falado e as suas possíveis consequências do que foi dito. Outra característica 
marcante é a retroalimentação imediata durante a comunicação, que vai interferir na elaboração da próxima fala.

Gómez (2004) menciona também as seguintes características da língua oral: a) frases incompletas ou interrompidas por outros interlocutores, b) escassez de esquemas de subordinação e uma presença maior de esquemas de coordenação ou justaposição, c) escasso uso da voz passiva, d) reformulação ou repetição de expressões para facilitar sua compreensão ou ainda a repetição do interlocutor, e) uso de um vocabulário reduzido, f) uso de pausas e expressões que servem como conectores discursivos, g) utilização de padrões, esquemas discursivos e rotinas conversacionais, h) abundancia de coloquialismos e vulgarismos, i) maior facilidade para passar de um assunto a outro, j) apoio constante de elementos linguísticos acústicos (ritmo, acento) e j) recurso frequente às expressões idiomáticas e frases feitas.

Na língua oral, também encontramos características como a entonação, pronunciação que são características de certo grau de dificuldade de serem aprendidos na aquisição de uma segunda língua -, pausas ou silencio e os elementos paralinguísticos - gestos, movimentos corporais ou faciais, situação espacial e a distância entre os interlocutores, etc. - e extralinguísticos - todo o contexto que envolve tanto os interlocutores como o assunto tratado - que servem como elementos que agilizam e facilitam a comunicação.

Diante dessas características, Gómez (2004) resume, ainda, as características da habilidade de expressão oral em agilidade, rapidez e espontaneidade, sendo essas características objetivos a serem alcançados pelos estudantes. Entre diferenças e semelhanças dessas destrezas básicas (oralidade e escrita) ao ser humano, é a forma oral, que é realizada pelo meio fônico, que todo indivíduo domina antes da escrita.

O linguista Marcuschi (2007) toma como base a definição de oralidade do linguista alemão Johannes Schwitalla (1997) que afirma que “a língua falada é um discurso livremente formulado, espontâneo, produzido em situações comunicativas autênticas, isto é, língua no sentido de uso linguístico e não de sistema linguístico".

Continuando, o autor faz um alerta para diferença entre oralidade e oralização, que apesar de terem como característica a realização por meio fônico, e se diferenciarem na forma de realização do funcionamento da escrita, que é por meio de manifestação gráfica, são diferentes visto que um texto escrito ao ser lido em voz alta não faz com que o texto oralizado se torne um texto falado (MARCUSCHI, 2007, p.68). 
Para o autor, a língua falada ou oralidade tem como traço importante sua produção na condição sonora e se processa em tempo real e de forma natural produzindo discursos reais e "que envolve estratégias típicas do ponto de vista da formulação" (MARCUSCHI, 2007, p.70), sendo que em um texto oralizado essas estratégias para a formulação não serão necessárias no sentido de que o texto já está formulado, ou seja, não foi produzido em tempo real à comunicação (diálogo ou monólogo).

Depois dessa breve definição de oralidade e a distinção entre oralidade e oralização, é pertinente, para nossa pesquisa, ver a oralidade do ponto de vista da aquisição de uma segunda língua. Segundo Gómez (2004), o objetivo de se aprender a expressar-se oralmente é a comunicação por parte do aluno. O Plano Curricular do Instituto Cervantes (1994) explica que essa aprendizagem da expressão oral supõe em uma L2 que o aprendiz possa se comunicar com um interlocutor real, em um tempo específico, tudo o que pensa ou o que precisa, tudo isso da maneira mais adequada possível a situação em que se encontra e ao que espera o interlocutor.

Para Poulisse (1999, p. 56, apud FALCÃO, 2016, p. 21), na oralidade de um aprendiz de L2, é preciso levar em consideração três diferenças importantes entre a produção em L1 e L2: 1) o conhecimento que o aprendiz tem em L2 é incompleto; 2) na L2, o discurso do aprendiz tem menor fluência que na L1; e 3) a L1 interfere na L2, principalmente quando o aprendiz não tem tanto domínio da L2.

\section{Teorias de aquisição de línguas}

Segundo Griffin (2005), a busca de uma teoria que explique a aquisição de línguas tem evoluído juntamente com o desenvolvimento de outras ciências cognitivas como a psicologia, a sociologia, a antropologia e a neurologia, que são ciências que tem fornecido novos dados para explicar um processo que é complexo e muito difícil de medir. $\mathrm{O}$ autor também afirma que são muitos os fatores que contribuem para que uma pessoa possa dominar uma língua e mais ainda quando se trata de uma segunda língua.

Larsen-Freeman e Long (1994, apud Griffin, 2005) propõem que as teorias que existem sobre Aquisição de segundas línguas (doravante ASL) sejam divididas em três categorias: ambientalistas, interacionistas e nativistas. A seguir, apresentamos cada uma delas. 
No campo da Psicologia, por décadas, foi debatido si é maior a influência da cognição interna ou a do entorno sobre a aprendizagem dos indivíduos, a partir dessas discussões é que surgem as teorias ambientalistas.

Para explicar a ASL, os ambientalistas propõem como base as relações sociais e os tipos de comunicação que surgem a partir de observações a indivíduos que se encontram em uma situação de obrigada aquisição de uma segunda língua, por exemplo, os imigrantes. Se denomina este tipo de processo "pidginização" ou "criolização" ou o que dá lugar a uma língua "pidgin". A verdade é que um pidgin é o resultado da aquisição parcial de uma L2 e que, portanto, revela fortes influencias da L1. A aquisição é motivada única e exclusivamente pela necessidade de se comunicar para efetuar uma atividade específica.

Essa teoria se diferencia das outras no sentido de não fazer observações a indivíduos que aprendem em contexto de sala de aula. Nesta teoria encontramos as teorias da aculturação, a desnativização e a acomodação.

Nas teorias Interacionistas, os estudos relacionados com o ato de se comunicar servem como base de duas teorias da ASL cujo foco principal gira em torno da interação e à aprendizagem que procede dela.

Concretamente, veremos a ASL desde a teoria do discurso (que não é uma teoria da ASL propriamente dita) que tem início na década de 70, onde os estudiosos da linguística aplicada começaram a fazer investigações sobre como os seres humanos comunicam-se entre si e como aprendem essa comunicação na L1 e na L2; e desde a teoria da variabilidade que nada mais é do que uma versão da teoria acima desde uma perspectiva mais sociocultural.

As teorias nativistas são aquelas que contemplam a ASL tomando como base as características das línguas mistas e sua natureza sistemática. A perspectiva é mais distanciada do indivíduo como comunicador na sociedade.

As origens das teorias nativistas vêm das reações de Chomsky ante o condutismo de Skinner. A aplicação das ideias de Chomsky à ASL ocorre desde uma base linguística dando a entender que o dispositivo de adquirir línguas capacita ao aprendiz relacionar dados que percebe de seu entorno com um sistema linguístico universal, uma espécie de modelo que permite ao aluno categorizar elementos para poder selecionar os mais apropriados segundo a necessidade comunicativa imediata.

No nativismo proposto por Stephen Krashen, é mencionado uma hipotética "rota natural" que é seguida por todos os aprendizes de uma L2, esse conceito é uma analogia à 
"Gramática universal” de Chomsky para a L1. Ou seja, segundo Griffin (2005), para esses autores há uma ordem natural de aquisição de uma L2 que a instrução formal pode até impulsionar esse processo, porém não pode modifica-la.

Essa teoria propõe que o progresso por esta rota é resultado de dois tipos de processo: a aquisição e a aprendizagem. A aquisição é um processo mais natural, espontâneo e inconsciente sem, necessariamente, a intervenção de uma instrução formal, já a aprendizagem de dá se forma contraria a aquisição, ela ocorre em um contexto escolar, de forma planejada, com atividades sistemáticas e de maneira mais consciente.

Cada uma dessas duas teorias que vimos mais acima na teoria Nativista - Condutismo de Skinner e o Nativismo de Chomsky e Krashen - tem seu próprio modelo de análise. São elas: análise contrastiva e análise de erros, esta veremos mais à frente.

\section{A interlíngua}

Segundo Baralo (2004), o estudo sobre aquisição de línguas estrangeiras nasceu junto às atividades de professores que se preocupavam por encontrar uma metodologia que pudesse ajudar aos seus alunos a não cometerem tantos erros quando se comunicassem na língua meta. Ainda segundo a autora, durante a análise das produções linguísticas dos alunos, se percebia que existiam produções bastante peculiares, que não pertenciam nem a língua materna e nem língua meta. Para Griffin (2005) e Cesteros (2006), esse processo onde o indivíduo se encontra em uma fase que transita de forma contínua entre as duas línguas, L1 e L2, é denominado Interlíngua (IL).

Com as propostas de Selinker (1972, apud Baralo, 2004 e Griffin, 2005) o término técnico Interlíngua, passou a se referir ao sistema linguístico não nativo citado acima. Griffin (2005), afirma que no processo de IL

\footnotetext{
Para progredir na aquisição de línguas, o indivíduo percebe a língua (a princípio incompreensível) do seu entorno, faz uma associação com seu conhecimento (a estrutura cognitiva), e gera hipóteses sobre os significados e usos. Depois, ensaia estas hipóteses de maneira ativa (usando a língua) ou passiva (observando como se usa a língua) e segundo a retroalimentação (compreensão ou incompreensão) produzida pelos ensaios, aceita ou rejeita as hipóteses. No caso de aceita-las, passa a fazer parte de seus conhecimentos; no caso de rejeitá-las, volta atrás e repete o mesmo processo de novo. (GRIFFIN, 2005, P.91)
}

Para ele, as estratégias usadas pelos alunos para formular as hipóteses são cinco: (1) transferência de L1: se trata de fazer traduções literais; o aluno usa palavras, estruturas; fragmentos de discurso etc. que possa fazer com que ele gere alguma hipótese; (2) super- 
generalização de regras: é quando o aluno aplica a regra em todas as situações parecidas sem levar em conta as exceções; (3) transferência de instrução: se assemelha a estratégia anterior, sendo que esta estratégia vem direto da explicação da regra; (4) estratégias de aprendizagem: são necessários muitos tipos de aprendizagem para avançar na interlíngua, Gagné (1965, apud Griffin, 2005) identificou oito tipos de aprendizagem e todos esses tipos de aprendizagem, para Griffin (2005) são importantes para se aprender uma L2 visto que o aprendiz utiliza essas estratégias como mecanismo para assimilar o input e aplica-lo no momento que considera adequado ;e (5) estratégias de comunicação: as estratégias de comunicação são aplicadas de formas consciente ou semiconsciente para solucionar problemas quando a mensagem não é bem transmitida fazendo com que seja amenizada a carga mental do aprendiz em processar um input muito acima dos conhecimentos.

\section{Análise de erros (AE)}

Segundo Fernández (1995) identificar e buscar corrigir os erros dos alunos é uma atitude didática quase inata a um professor de línguas. No entanto, a autora afirma que na análise de erros (AE) se tem uma divisão do erro diferente da corrente Condutista, seus métodos de investigação também se diferenciam visto que a $\mathrm{AE}$ não tem como base principal em sua investigação a transferência da LM para a L2. Suas análises partem das produções reais dos alunos, e percorre os seguintes passos definidos por Corder (1981)

1. Identificação dos 'erros' em seu contexto, 2. Classificação e descrição, 3. Explicação, buscando os mecanismos ou estratégias psicolinguísticas e as fontes de cada erro (neste ponto entra a possível interferência da LM, como uma estratégia a mais). 4. Si a análise tem pretensões didáticas, se avalia a gravidade do erro e se busca a possível terapia. (CORDER, 1981, p. 14-26, apud Fernández 1995)

Nesta corrente, a concepção de erro é também totalmente diferente da que se tem na análise contrastiva. Na AE o erro é tido como passo imprescindível para a aprendizagem de uma nova língua e também pode ser visto como um marcador do progresso do aluno durante a aprendizagem.

Segundo Fernández (1995), esta corrente surge a partir dos trabalhos de Chomsky e das pesquisas feitas sobre aquisição da LM e a aplicação à aquisição da L2. Para a AE, segunda a autora, a aquisição de uma língua por uma criança é um "processo criativo" no qual uma espécie de mecanismo inato constrói a gramática de determinada língua a partir do input que a criança recebe, igualmente, se presume "que algumas das estratégias adotadas pelo 
aprendiz de uma língua estrangera podem ser substancialmente as mesmas que permitem a aquisição da L1”(CORDER 1981, p. 7, apud FERNÁNDEZ 1995)

Os erros são considerados aceitáveis no processo de interlíngua e são usados, por vezes, pelos alunos, como estratégias para a aquisição da língua meta como vemos em Fernández (1995) e Corder (apud Fernandéz, 1981). Apesar de sua normalidade, devem ser superados para que se possa haver uma comunicação eficaz e satisfatória entre todas as partes envolvidas em determinada comunicação.

\section{Metodologia}

A referida pesquisa pode ser classificada como descritiva, já que busca observar e registrar os fatos ocorridos de modo a descrevê-los sem que haja interferência por parte do pesquisador. Já no que se refere à abordagem do problema e análise dos dados, classificamos nossa pesquisa como quanti-qualitativa.

\section{Resultados e Discussão}

Para tentar responder as nossas questões teóricas, fizemos um apanhado do ponto de vista de algumas teorias de aquisição e oralidade, para a partir disso expormos nosso resultado. Sobre a primeira questão "Podemos dizer que sempre que um aprendiz de uma segunda língua comete um erro é por causa da língua materna?”, entendemos, assim como Griffin (2005), que diversos fatores contribuem para que uma pessoa possa dominar uma língua e, mais ainda, quando se trata de uma segunda língua.

Vimos também que, para Larsen-Freeman e Long (1994, apud Griffin, 2005), as teorias que existentes sobre ASL podem ser divididas em três categorias, que são elas: ambientalistas, interacionistas e nativistas. Na corrente ambientalista, é descrito um fenômeno chamado de pidgin, como já vimos no nosso referencial, que é o resultado da aquisição parcial de uma L2 e que, portanto, revela fortes influencias da L1. A aquisição é motivada única e exclusivamente pela necessidade de se comunicar para efetuar uma atividade específica.

Portanto, podemos perceber facilmente que, nessa teoria, que aponta uma L2 mesclada, a L1 terá a grande maioria de seus erros como erros interlinguais, porém esse tipo de aquisição é muito específico, já que não tem uma intervenção formal para a aprendizagem da língua. Não traremos as teorias interacionistas como argumento para responder a nossa 
questão porque não é uma teoria da ASL propriamente dita, é mais uma versão da teoria acima desde uma perspectiva mais sociocultural.

Já nas teorias nativistas, são mencionados a "rota natural", propostas por Stephen Krashen, e a "Gramática universal", de Chomsky, que nada mais são do que, como explica Griffin (2005), uma ordem natural e comum de aquisição de uma L2. Selinker (1972, apud Baralo, 2004 e Griffin, 2005) Interlíngua: Como já foi visto, a escritora Baralo (2004) relata que ao analisar as produções linguísticas dos alunos, pode perceber que existiam produções peculiares, que não pertenciam nem a língua materna e nem língua meta, assim foi definido como Interlíngua a fase em que o aprendiz transita de forma contínua entre as duas línguas, Griffin (2005) e Cesteros (2006).

Nessa etapa da aprendizagem, o aluno vai criar suas hipóteses e testá-las de formas ativas, ou seja, cometerá erros e acertos (GRIFFIN, 2005, P.91). O modo como vai formular suas hipóteses também definirá a origem de seus erros que poderão ser: (1) transferência da L1; (2) super-generalização de regras da L2; (3) transferência de instrução; (4) estratégias de aprendizagem; e (5) estratégias de comunicação. Portanto, nesta corrente teórica, a interferência da LM é apontada como uma estratégia a mais utilizada pelo aprendiz para formular suas hipóteses (CORDER, 1981, p. 14-26, apud Fernández 1995), e não como o único meio.

Com relação à nossa segunda pergunta, "Como podemos diferenciar oralidade de oralização no processo de aquisição de línguas?", primeiramente, entendemos que tanto a fala oral quanto a oralizada são realizadas e tem como condição mínima a realização pelo meio fônico. Além disso, tanto na fala oral quanto na fala oralizada podemos encontrar traços como frases incompletas ou interrompidas por outros interlocutores, entonação, pronunciação (sugeridos pela pontuação gráfica) e rapidez, entretanto, apesar dessas características em comum entre oralidade e oralização, elas são diferentes, visto que um texto escrito ao ser lido em voz alta não faz com que o texto oralizado se torne um texto falado (MARCUSCHI, 2007, p.68).

No texto falado encontramos características como o processamento em tempo real, espontaneidade, fala imediata, agilidade, escassez de esquemas de subordinação e uma presença maior de esquemas de coordenação ou justaposição, escasso uso da voz passiva, reformulação ou repetição de expressões para facilitar sua compreensão ou ainda a repetição do interlocutor, uso de um vocabulário reduzido, uso de pausas e expressões que servem 
como conectores discursivos, utilização de padrões, esquemas discursivos e rotinas conversacionais, abundancia de coloquialismos e vulgarismos, maior facilidade para passar de um assunto a outro, apoio constante de elementos linguísticos acústicos (ritmo, acento) e recurso frequente às expressões idiomáticas e frases feitas. E isso tudo de forma natural, produzindo discursos reais e que exigem estratégias para sua formulação (MARCUSCHI, 2007), sendo que no texto oralizado essas estratégias para a formulação não serão necessárias uma vez que o texto já está formulado, ou seja, não foi produzido nem em tempo real à comunicação (diálogo ou monólogo), nem há espontaneidade, as pressões psicológicas para uma resposta em tempo hábil não existem e tantas outras características citadas à próprias da oralidade.

\section{Conclusões}

Concluímos, então, que a língua materna não pode ser considerada a única possível causa do erro visto que fatores intralinguais, como a super-generalização de regras, também podem levar ao erro.

Quanto à diferença entre oralidade e oralização, concluímos que ambas têm aspectos semelhantes, porém, a fala oral mostra-se mais complexa que oralizar um texto escrito, enquanto para oralizar um texto é necessário ter domínio das regras de pontuação, a fala oral requer estratégias para sua formulação em tempo real, ágil e até para preencher as pausas na fala.

Outra característica marcante é a retroalimentação imediata durante a comunicação, que vai interferir na elaboração da próxima fala, ou seja, a comunicação vai sendo construída coletivamente, de acordo com as reações de cada pessoa ante o falado pelo outro.

\section{Referências}

BARALO, Marta. La adquisición del español como lengua extranjera. $2^{\circ}$ ed. Madrid: 2004.

BARBOSA, Louise Alane Martins. Análise de erros de Interlíngua na produção escrita de alunos da licenciatura em espanhol do IFRN. 2017. 57 f. Trabalho de Conclusão de Curso (Graduação em Letras espanhol) - Instituto Federal de Educação, Ciência e Tecnologia do Rio Grande do Norte, Natal, 2017.

CESTEROS, Susana Pastor. Aprendizaje de segundas lenguas: lingüística aplicada a la enseñanza de idiomas. Publicaciones Universidad de Alicante, 2006. 
FALCÃO, Carla Aguiar. Produção Oral em Espanhol como L2 e Educação a Distância: diálogos e práticas possíveis. Natal, 2016.

FARIAS, Maria Solange. Estudo da Interlíngua de Brasileiros estudantes de espanhol apoiado na Análise de Erros. Fortaleza, 2007.

FERNÁNDEZ, Sonsoles. Errores e interlengua en el aprendizaje del español como lengua extranjera. In: Didáctica, 7. Madrid: Sevicio de Publicaciones de la UCM, 1995. Acesso em 24/04/2018. Dísponivel em:

< https://revistas.ucm.es/index.php/DIDA/article/viewFile/DIDA9595110203A/2005>

Interlengua y Análisis de Errores en el aprendizaje del español como lengua extranjera. Espanha: Edelsa Grupo Didascalia S. A., 1997.

GÓMEZ, Raquel Pinilla. Las habilidades lingüísticas y comunicativas. In: LOBATO, Jesús Sánchez; GARGALLO, Isabel Santos. Vademécum para la formación de profesores: Enseñar español como segunda lengua (L2)/lengua extranjera (LE). Madrid: SGEL-Educación, 2004.

GRIFFIN, Kim. Lingüística aplicada a la enseñanza del español como 2/L. Madrid: Arco Libros, 2005.

MARCUSCHI, Luiz Antônio, et al. Fala e escrita. 1 ed. Belo Horizonte: Autêntica, 2007.

MOYSÉS, Juliana Jere. Um estudo de Interlíngua: análise de erros em espanhol cometidos por falantes do português na graduação. São Paulo, 2014.

QUIÑONES, Virginia de Alba. El análisis de errores en el campo del español como lengua extranjera. Universidad Pablo de Olavide. Acesso em 24/04/2018. Dísponivel em: <https://www.nebrija.com/revistalinguistica/files/articulosPDF/articulo_5316e9a63dc81.pdf> 